\title{
Choice of the surgical approach for patients with stage I lung squamous cell carcinoma $\leq 3 \mathrm{~cm}$
}

\author{
Chunji Chen ${ }^{1 \#}$, Yiyang Wang ${ }^{1 \#}$, Xufeng Pan ${ }^{1 \#}$, Shijie Fu ${ }^{1}$, Yubo Shi ${ }^{2}$, Jun Yang ${ }^{1}$, Rui Wang ${ }^{1}$ \\ ${ }^{1}$ Department of Thoracic Surgery, Shanghai Chest Hospital, Shanghai Jiao Tong University, Shanghai 200030, China; ${ }^{2}$ Department of Thoracic \\ Surgery, Yantaishan Hospital, Yantai 264001, China \\ Contributions: (I) Conception and design: R Wang; (II) Administrative support: R Wang, J Yang; (III) Provision of study materials or patients: C Chen, \\ Y Wang; (IV) Collection and assembly of data: X Pan, S Fu, Y Shi; (V) Data analysis and interpretation: C Chen, Y Wang; (VI) Manuscript writing: \\ All authors; (VII) Final approval of manuscript: All authors. \\ \#These authors contributed equally to this work. \\ Correspondence to: Jun Yang; Rui Wang. Department of Thoracic Surgery, Shanghai Chest Hospital, Shanghai Jiao Tong University, 241 West Huaihai \\ Road, Shanghai 200030, China. Email: yangjun_chest@126.com; rui_wang788@163.com.
}

Background: We tried to explore the surgical procedures for stage I squamous cell carcinoma (SCC) with a size of $\leq 3 \mathrm{~cm}$ by using the Surveillance, Epidemiology, and End Results (SEER) database. Furthermore, we investigated the relationships between the chosen surgical option and the size of SCC.

Methods: In total, 1,147 patient data sets were collected from 2010 to 2011 using the SEER database. Afterwards, 849 patients with a pT1-2aN0M0 SCC with a size of $\leq 3 \mathrm{~cm}$ after a lobectomy or sublobectomy procedure were identified. Kaplan-Meier curves were conducted to compare the overall survival (OS) rates and the lung cancer-specific survival (LCSS) rates between the two surgical approaches. Cox proportional hazards regressions were performed to discover the independent risk factors for both the OS and LCSS rates. Lastly, subgroup analysis was stratified by the size of the SCC and then classified by the $8^{\text {th }}$ edition T category.

Results: The sublobectomy procedure did not demonstrate a difference for the OS rate. Additionally, it demonstrated a worse LCSS rate when compared with a lobectomy for stage I SCC. In the subgroup analysis, a lobectomy was shown to have a better survival outcome only when the SCC was $>2$ and $\leq 3 \mathrm{~cm}$. Multivariable analysis showed that a size of $>2$ to $\leq 3 \mathrm{~cm}$, and an age of $>60$ were independently associated with poorer OS while the sublobectomy procedure and pleural invasions (PI) were related with a poorer LCSS rate. In the stratification of data for the tumor size, the cox proportional analysis still confirmed the protective effects of the lobectomy in subgroups of SCCs with sizes between $>2$ to $\leq 3 \mathrm{~cm}$ as well as the T1c category.

Conclusions: The choice of the SCC surgery can be recommended based on the tumor size. A lobectomy procedure demonstrated a better LCSS against the sublobectomy in stage I SCC. SCC with sizes of $>2$ to $\leq 3 \mathrm{~cm}$ could become a pretty good indicator for lobectomy, while a sublobectomy may be an adequate substitute when the SCC size is $\leq 2 \mathrm{~cm}$, especially for patients who cannot tolerate a lobectomy. T1c category can also suggest a lobectomy instead of sublobectomy for stage I SCC patients.

Keywords: Stage I squamous cell carcinoma (stage I SCC); lobectomy; sublobectomy

Submitted Jul 16, 2018. Accepted for publication Oct 25, 2018.

doi: $10.21037 /$ jtd.2018.11.51

View this article at: http://dx.doi.org/10.21037/jtd.2018.11.51 


\section{Introduction}

Lung cancer has been the leading cause of cancer-related mortality in the world, especially in China $(1,2)$. As one of the major pathological types of non-small cell lung cancers (NSCLC), squamous cell carcinomas (SCC) accounted for about $20-30 \%$ of the NSCLC cases $(3,4)$. With the increasing use of computed tomography (CT) scanning technology, and low-dose computed tomography (LDCT) for screening and examination, large amounts of smallsized NSCLC have been detected in recent years, most of which were small-sized peripheral lung adenocarcinomas (ADCs) among nonsmoker patients, while at the same time, patients with SCC in the early stage were still growing gradually $(5,6)$.

Since the randomized controlled trials (RCT) that were performed by the Lung Cancer Study Group in 1995, lobectomy and lymph node dissection has been widely recognized as the recommended standard treatment for stage I NSCLC patients (7). Since 1990, there has still been a heated debate about which surgical decision should be made for stage I NSCLC patients: a lobectomy or a sublobectomy (8). It was well-known that a lobectomy procedure has a much lower local and distant recurrence rate and a better survival outcome when compared with a sublobectomy (including wedge resection and a segmentectomy) among clinical stage I NSCL. It has even been shown to have a priority for aging patients with a size below $2 \mathrm{~cm}(9,10)$. On the contrary, a sublobectomy procedure was still wildly used in NSCLC surgical procedures, especially for small-sized NSCLCs $(11,12)$, and even more especially for those patients with a compromised cardiorespiratory function or disease (13).

Although several studies have discussed the proper surgical approaches for stage I NSCLC, no specified research focusing on small-sized SCC was found. Thus, the optimal surgical decision for SCC in the early stage remains unclear. In this study, we attempted to discover the appropriate surgical choice for patients with stage I SCC through the large Surveillance, Epidemiology, and End Results (SEER) database.

\section{Methods}

\section{Patients}

We selected a total of 1,147 patients with pathological T12aN0M0 lung squamous carcinoma $\leq 3 \mathrm{~cm}$ who underwent a lobectomy or sublobectomy procedure from January 2010

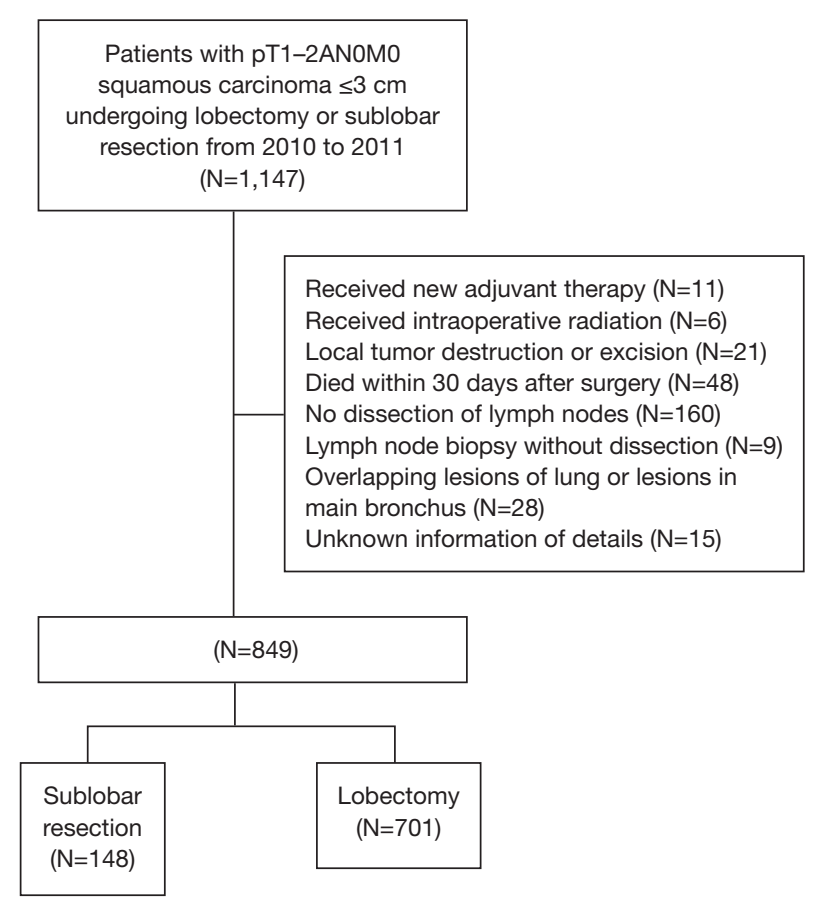

Figure 1 Study cohort flowchart. 1,147 patients with stage I SCC $\leq 4 \mathrm{~cm}$ who underwent lobectomy or sublobectomy were collected between 2010 and 2011. After all exclusion criteria were applied, 849 patients were identified. SCC, squamous cell carcinoma

to December 2011 in the SEER database (14). Candidates would be included in our study if the inclusion criteria was met, and were excluded if the exclusion criteria were met as per Figure 1. After the exclusion process, a sum of 849 patients was deemed eligible for this research study.

In this retrospective study, the baseline characteristics including patient-related information (gender, age, race), treatment-related information (post-radiotherapy, type of surgery, number of harvested lymph node) and tumorrelated information [lobe, laterality, size of tumor, $\mathrm{T}$ classification and pathological stage according to the $8^{\text {th }}$ edition of the TNM classification, differentiation of tumor, pleural invasion (PI)] were all collected from the SEER Database. All candidates were classified into 2 groups in accordance with the surgical approach: a lobectomy group and a sublobectomy group.

The primary endpoint for the study was the overall survival (OS) rate. This was calculated by using the datasets from the date of the operation to the date of the patient's last follow-up or death. The lung cancer-specific survival (LCSS) rate was the secondary endpoint in our study, which was defined as the interval time between the operation and 
Table 1 Clinicopathological characteristics of patients with pT1-2aN0M0 squamous cell carcinoma $\leq 3 \mathrm{~cm}$ who underwent sublobectomy or lobectomy

\begin{tabular}{|c|c|c|c|}
\hline Variable & $\begin{array}{l}\text { Sublobectomy } \\
\qquad(\mathrm{N}=148)\end{array}$ & $\begin{array}{l}\text { Lobectomy } \\
\qquad(\mathrm{N}=701)\end{array}$ & $P$ \\
\hline Sex & & & 0.072 \\
\hline Male & $68(45.9)$ & $379(54.1)$ & \\
\hline Female & $80(54.1)$ & $322(45.9)$ & \\
\hline Age (years) & & & 0.009 \\
\hline$\leq 60$ & $10(6.8)$ & $104(14.8)$ & \\
\hline$>60$ & 138 (93.2) & 597 (85.2) & \\
\hline Race & & & 0.559 \\
\hline White & $128(86.5)$ & 617 (88.0) & \\
\hline Black & $15(10.1)$ & $54(7.7)$ & \\
\hline Others & $5(3.4)$ & $30(4.3)$ & \\
\hline Lobe & & & 0.252 \\
\hline Upper & $97(65.5)$ & $442(63.1)$ & \\
\hline Middle & $4(2.7)$ & $43(6.1)$ & \\
\hline Lower & $47(31.8)$ & $216(30.8)$ & \\
\hline Laterality & & & 0.286 \\
\hline Left & $70(47.3)$ & $298(42.5)$ & \\
\hline Right & $78(52.7)$ & 403 (57.5) & \\
\hline Post-Radio & & & 0.268 \\
\hline No & 144 (97.3) & 691 (98.6) & \\
\hline Yes & $4(2.7)$ & $10(1.4)$ & \\
\hline Pathology & & & 0.332 \\
\hline Keratinizing & $11(7.5)$ & 34 (4.9) & \\
\hline $\begin{array}{l}\text { Non- } \\
\text { keratinizing }\end{array}$ & $3(2.0)$ & 27 (3.9) & \\
\hline Basaloid & $0(0)$ & $6(0.8)$ & \\
\hline Clear cell & $0(0)$ & $3(0.4)$ & \\
\hline Unknown & $134(90.5)$ & $631(90.0)$ & \\
\hline Size (cm) & & & 0.007 \\
\hline$\leq 1$ & $17(11.5)$ & $40(5.7)$ & \\
\hline$>1$ and $\leq 2$ & $75(50.7)$ & $319(45.5)$ & \\
\hline$>2$ and $\leq 3$ & $56(37.8)$ & $342(48.8)$ & \\
\hline $\mathrm{T}$ & & & 0.002 \\
\hline T1a & $17(11.5)$ & $33(4.7)$ & \\
\hline T1b & 65 (43.9) & $278(39.7)$ & \\
\hline $\mathrm{T} 1 \mathrm{c}$ & $39(26.4)$ & 268 (38.2) & \\
\hline $\mathrm{T} 2 \mathrm{a}$ & 27 (18.2) & $122(17.4)$ & \\
\hline Stage & & & 0.807 \\
\hline $\mathrm{IA}$ & $121(81.8)$ & 579 (82.6) & \\
\hline IB & 27 (18.2) & $122(17.4)$ & \\
\hline
\end{tabular}

Table 1 (comtinued)
Table 1 (comtinued)

\begin{tabular}{lccc}
\hline Variable & $\begin{array}{c}\text { Sublobectomy } \\
(\mathrm{N}=148)\end{array}$ & $\begin{array}{c}\text { Lobectomy } \\
(\mathrm{N}=701)\end{array}$ & $\mathrm{P}$ \\
\hline Differentiation & & $29(4.1)$ & 0.706 \\
Well & $8(5.4)$ & $370(52.8)$ & \\
Moderate & $74(50.0)$ & $302(43.1)$ & \\
Poor & $66(44.6)$ & & $<0.001$ \\
LN & & $434(61.9)$ & \\
$\leq 10$ & $124(83.8)$ & $267(38.1)$ & \\
$>10$ & $24(16.2)$ & & \\
PI & & $579(82.6)$ & \\
No & $121(81.6)$ & $122(17.4)$ & \\
Yes & $27(18.2)$ & & \\
\hline
\end{tabular}

Data are shown as number (percentage). Post-Radio, postradiotherapy; T, T classification; Stage, pathological stage; LN, harvested lymph nodes; PI, pleural invasion.

the patient's death due to lung cancer.

\section{Statistical analysis}

The categorical variables were calculated by Pearson $\chi^{2}$ or Fisher's exact test. Kaplan-Meier curves were plotted with GraphPad (Prism 5) to analyze the OS and LCSS between the two groups, which were identified using the Log-rank test. Cox proportional hazards regressions were conducted to discover the potential and independent risk factors for the OS and LCSS in pathological T1-2aNOM0 SCC with a size $\leq 3 \mathrm{~cm}$ who had undergone a lobectomy or a sublobectomy by the usage of a SPSS 20.0. Statistical significance was set as a two-sided $\mathrm{P}<0.05$.

\section{Results}

\section{Patient characteristics}

There were a total of 849 patients with pT1-2aN0M0 SCC (size $\leq 3 \mathrm{~cm}$ ) enrolled in this study, including 148 patients who underwent a sublobectomy and 701 patients who underwent a lobectomy. The median follow-up time was 29.17 months for sublobectomy and 31.29 months for lobectomy, in which 191 patients died (38 patients of the sublobectomy and 153 of the lobectomy) and 97 patients suffered from lung cancer-specific deaths (24 patients of the sublobectomy group and 73 of the lobectomy group). The baseline characteristics of the primary cohort are all presented in Table 1, from which we could verify that when a 
sublobectomy was performed it was more likely in the elder SCC patients $(\mathrm{P}=0.009)$ and had a smaller size $(\mathrm{P}=0.007)$, especially in the size of $\leq 2 \mathrm{~cm}$. Also, a different number of harvested lymph nodes emerged owing to a different surgical approach $(\mathrm{P}<0.001)$. When subgrouping our cohort according to tumor size, there were almost no significant differences between the two groups expect for harvested lymph nodes (Table 2).

\section{OS}

In survival analyses of the overall survival, sublobectomy did not demonstrate a significant difference in the 5 -year OS rate (lobectomy vs. sublobectomy: $73.0 \%$ vs. $67.3 \%$, $\mathrm{P}=0.210$ ) when compared with a lobectomy procedure for those patients with SCC with a size of $\leq 3 \mathrm{~cm}$ (Figure 2). When subgrouping SCC into $\leq 1,>1$ to $\leq 2 \mathrm{~cm}$ and $>2$ to $\leq 3 \mathrm{~cm}$, there was no obvious difference statistically in the 5 -year OS (lobectomy vs. sublobectomy $\leq 1 \mathrm{~cm}$ : $93.8 \%$ vs. $82.5 \%, \mathrm{P}=0.287$; lobectomy vs. sublobectomy $>1$ to $\leq 2 \mathrm{~cm}$ : $80.8 \%$ vs. $76.1 \%, \mathrm{P}=0.538$ ) (Figure $3 A, B$ ). On the contrary, prominent discrepancy was demonstrated between the SCC group with a size of $>2$ to $\leq 3 \mathrm{~cm}$, strongly indicating a much better 5-year OS (lobectomy vs. sublobectomy: 69.2\% vs. $41.6 \%, \mathrm{P}=0.001$ ) for those patients who had underwent a lobectomy rather than a sublobectomy (Figure 3C).

Cox proportional hazards regressions were then performed to analyze the potential risk factors of the OS rate for patients with SCC $\leq 3 \mathrm{~cm}$. The sizes of $>2$ to $\leq 3 \mathrm{~cm}$ revealed an independent significance with poor survival outcome ( $\mathrm{HR}=2.158 ; 95 \% \mathrm{CI}, 1.052-4.426 ; \mathrm{P}=0.036$ ) as well as in those aged $>60$ (HR $=1.826 ; 95 \%$ CI, 1.094-3.048; $\mathrm{P}=0.021)$, while $\mathrm{PI}(\mathrm{P}=0.061)$ and size $>1$ to $\leq 2 \mathrm{~cm}(\mathrm{P}=0.359)$ seemed to have no statistical difference revealed through multivariable analysis (Table 3).

\section{LCSS}

In the analyses of LCSS, lobectomy still indicated a better 5-year LCSS rate (lobectomy vs. sublobectomy: $86.2 \%$ vs. $80.2 \%, \mathrm{P}=0.031)$ when contrasted with sublobectomy procedure (Figure 2). LCSS did not show a statistical difference between tumor sizes $\leq 1$ or $>1$ to $\leq 2 \mathrm{~cm}$ (lobectomy vs. sublobectomy $\leq 1 \mathrm{~cm}$ : $93.8 \%$ vs. $92.4 \%, \mathrm{P}=0.844$; lobectomy $v s$. sublobectomy $>1$ to $\leq 2 \mathrm{~cm}: 89.9 \%$ vs. $88.9 \%$, $\mathrm{P}=0.908$ ) (Figure 3D,E). However, only SCC with sizes of $>2$ to $\leq 3 \mathrm{~cm}$ demonstrated a better LCSS (lobectomy $v s$. sublobectomy: $83.0 \%$ vs. $61.5 \%, \mathrm{P}<0.001$ ) when undergoing lobectomy (Figure 3F).

We also performed Cox proportional hazards regressions to discover the potential risk factors for LCSS. Specifically, the lobectomy was considered to be a protective factor (HR $=0.561 ; 95 \%$ CI, 0.352-0.895; $\mathrm{P}=0.015)$. PI also showed differences in statistics (HR $=1.581 ; 95 \%$ CI, 1.002 2.493; $\mathrm{P}=0.049$ ) while the tumor size was observed to have no statistical influence on the survival outcome (Table 3).

\section{Subgroup analysis}

In addition, we further analyzed the two cohorts in the different $T$ stage according to the $8^{\text {th }}$ edition of the TNM classification through a Kaplan-Meier survival analysis. In the group of T1c, the lobectomy contained significant differences between better 5-year OS (lobectomy $v s$. sublobectomy: $71.5 \%$ vs. $42.8 \%, \mathrm{P}=0.001)$ and LCSS rate (lobectomy vs. sublobectomy: $84.8 \%$ vs. $66.6 \%, \mathrm{P}=0.001$ ) when compared with a sublobectomy procedure. While in other groups of $\mathrm{T}$ classifications, both surgical approaches did not show a statistical discrepancy (Figure S1).

Furthermore, Cox regressions were also conducted under the stratification of the tumor size (Table 4). Compared with sublobectomy in the group of sizes of $\leq 1$ and $>1$ to $\leq 2 \mathrm{~cm}$, a lobectomy procedure only revealed the superiority of a better 5 -year OS (HR $=0.520 ; 95 \% \mathrm{CI}$, $0.322-0.559 ; \mathrm{P}=0.008)$ and LCSS rate $(\mathrm{HR}=0.413 ; 95 \%$ CI, 0.223-0.764; $\mathrm{P}=0.005)$ in the group of size $>2$ to $\leq 3 \mathrm{~cm}$, which conformed to what we discovered in Figure 3. These results also indicated the potential risk of post-radiotherapy for those patients with SCC the sizes of $>1$ to $\leq 2 \mathrm{~cm}$ which may suffer from worse OS rate (HR $=7.618 ; 95 \%$ CI, $1.531-37.90 ; \mathrm{P}=0.013)$. Furthermore, the subgroup analysis of the clinicopathological characteristics of the T category among SCC patients with sizes of $\leq 3 \mathrm{~cm}$, are all listed in Table $S 1$. With respect to multivariable analysis, a lobectomy demonstrated significant difference against a sublobectomy procedure only in the case of T1c category (Table S2).

\section{Discussion}

Although a lobectomy has been the recommended treatment option for stage I NSCLC for decades (7), it has been challenged by sublobectomy in recent years as the preferred procedure (segmentectomy and wedge resection), especially for small-sized NSCLCs $(11,12)$. Regardless of approach type, about $30 \%$ patients with stage I NSCLC shall be confronted with a recurrence and death within 
Table 2 Clinicopathological characteristics of patients with squamous cell carcinoma (SCC) $\leq 1,>1$ to $\leq 2 \mathrm{~cm}$ and $>2$ to $\leq 3 \mathrm{~cm}$ who underwent sublobectomy or lobectomy

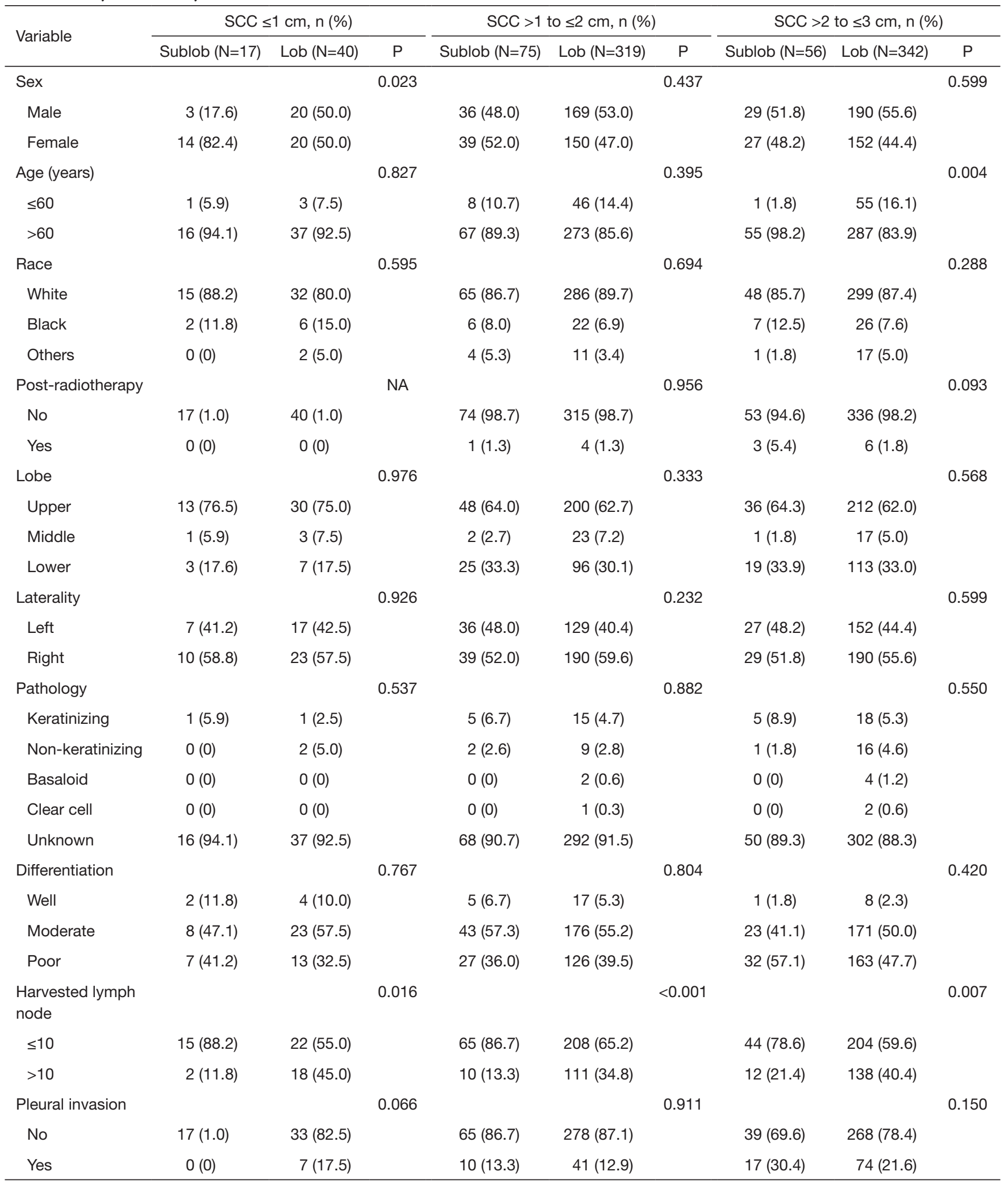




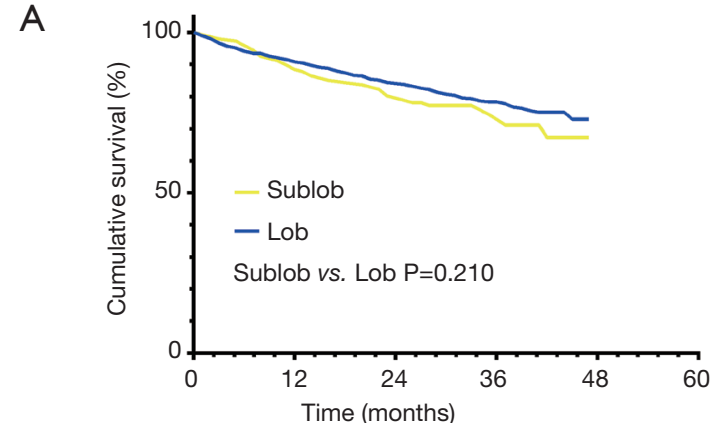

No. at risk Sublob Lob

$$
\begin{aligned}
& 148 \\
& 70
\end{aligned}
$$

B

No. at risk

Sublob

Lob

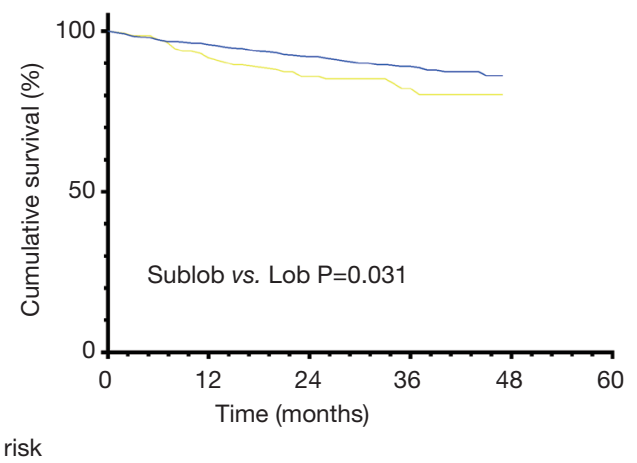

$\begin{array}{lllcll}148 & 129 & 113 & 43 & / & / \\ 701 & 634 & 563 & 254 & / & /\end{array}$

Figure 2 5-year overall survival (A) and lung cancer-specific survival (B) in patients with stage I squamous cell carcinoma (SCC) $\leq 3 \mathrm{~cm}$ who underwent lobectomy and sublobectomy.

5 years after thoracic surgery (15). As one of the major components of NSCLC, SCC demonstrated significant differences on either the clinicopathological or the genetic features when it was compared with $\mathrm{ADC}$, and even showed a worse outcome than ADC for the early stage patients (16). Therefore, it was reasonable for us to independently and individually make a correct and appropriate choice of the surgical approach for SCC. With regard to this research, a lobectomy promoted no difference in the total overall survival rate when contrasted with a sublobectomy among the patients with a stage I SCC which is consonant with the findings from Landreneau et al. which showed that there was no difference of survival which has ever existed between a lobectomy and sublobectomy in the early stage of NSCLC patients (11). On the contrary, the superiority of a traditional lobectomy was revealed among those patients under the circumstance of LCSS (Figure 2 and Table 3), which indicated that lobectomy could definitely reduce the risk of cancer-specific recurrence and death among early stage SCC patients.

It was well-known that the surgical choices of patients with stage I ADC depended on the size of the tumor and the subtypes of pathology $(12,17)$. Dai et al. reported that a lobectomy demonstrated superiority, when compared to a sublobectomy, in the patients with NSCLC tumor sizes of $\leq 2 \mathrm{~cm}$, and that sublobectomy could be considered for selected candidates with tumors $\leq 1 \mathrm{~cm}$ in size (12). Our previous study elucidated that it was the pathological subtypes of ADC that were crucial to the decision of certain surgical treatment during surgical operations: a non-invasive ADC (AAH/AIS/MIA) was suitable for a sublobectomy, while an invasive ADC including acinar, papillary, solid and micropapillary predominant ADC was appropriate for a lobectomy and lymph node dissection (17). With respect to the subtypes of the pathology of SCC, several studies have declared that either the subtypes (including keratinizing, non-keratinizing, basaloid and clear cell one) or the degree of keratinization (well, moderately and poorly differentiated) showed no significant differences in the clinical and other prognoses (18-20). In this study, similar results were revealed in that neither subtype $(\mathrm{P}=0.916$ for OS; $\mathrm{P}=0.983$ for LCSS) nor the degree of differentiation $(\mathrm{P}=0.446$ for OS; $\mathrm{P}=0.134$ for LCSS) was critical to the prognosis of patients with stage I SCC. Instead of subtypes or differentiation of the early stage SCC, we observed that there was evidence of that tumor size definitively corresponded with the proper choices of surgical approach on those patients with stage I SCC. This fact strongly suggests that a lobectomy could become the recommended and precedent procedure if the size of SCC is larger than $2 \mathrm{~cm}$. Additionally, a sublobectomy procedure showed no disparity against a lobectomy in the statistics on the overall or cancer-specific survival, which may be accepted as an optional alternative approach when SCC $\leq 2 \mathrm{~cm}$ especially for those patients with older age or a compromised cardiorespiratory function (21).

In the $8^{\text {th }}$ edition of the TNM classification of lung cancer, which changed from the $7^{\text {th }}$ edition, T1 categories are broken down by tumor size, which are classified into T1a, T1b and T1c, while T2a is defined as once visceral PI occurs, regardless of size $(22,23)$. In our study, we further discussed the potential influence of new T1 classifications 
A

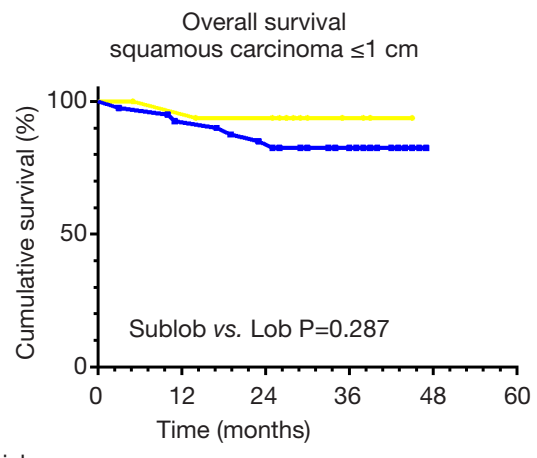

No. at risk

$\begin{array}{lllcccc}\text { Sublob } & 17 & 16 & 15 & 4 & / & \text { / } \\ \text { Lob } & 40 & 37 & 34 & 18 & / & \text { / }\end{array}$

B

Overall survival squamous carcinoma $>1$ to $\leq 2 \mathrm{~cm}$

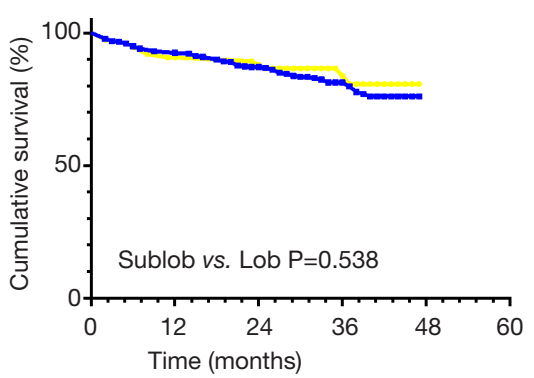

No. at risk

$\begin{array}{lcccccc}\text { Sublob } & 75 & 67 & 62 & 28 & / & / \\ \text { Lob } & 319 & 293 & 266 & 117 & / & /\end{array}$

C

Overall survival squamous carcinoma $>2$ to $\leq 3 \mathrm{~cm}$

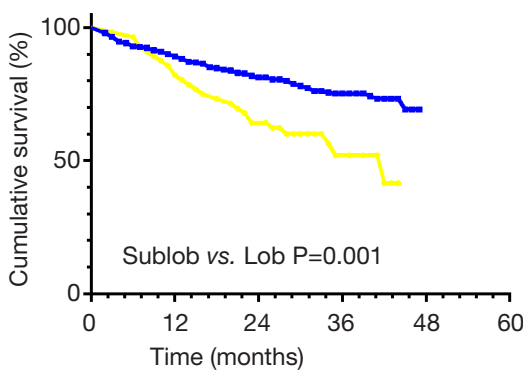

No. at risk

Sublob

Lob

$$
56
$$

D

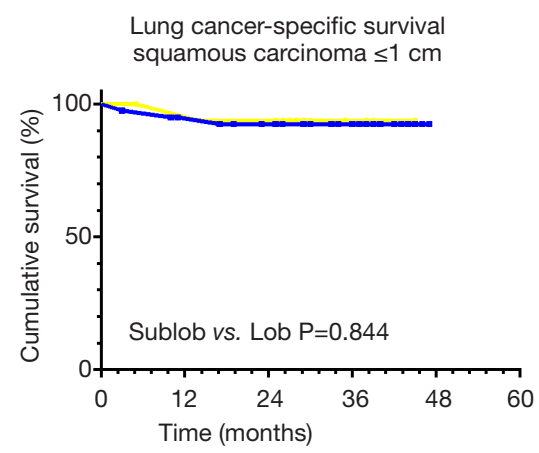

No. at risk

$\begin{array}{llllcll}\text { Sublob } & 17 & 16 & 15 & 4 & / & \text { / } \\ \text { Lob } & 40 & 37 & 34 & 18 & / & /\end{array}$

E

Lung cancer-specific survival squamous carcinoma $>1$ to $\leq 2 \mathrm{~cm}$

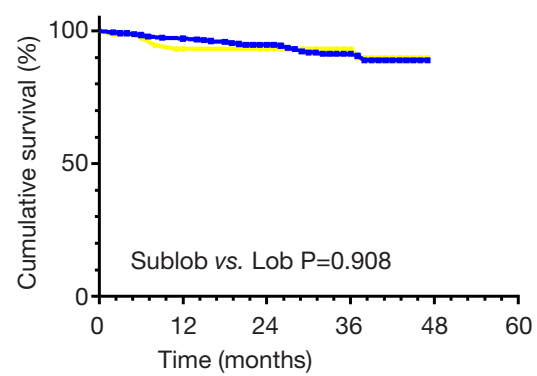

No. at risk

$\begin{array}{lllllll}\text { Sublob } & 75 & 67 & 62 & 28 & / & /\end{array}$

$\begin{array}{lllllll}\text { Lob } & 319 & 293 & 266 & 117 \quad / \quad /\end{array}$

F Lung cancer-specific survival squamous carcinoma $>2$ to $\leq 3 \mathrm{~cm}$

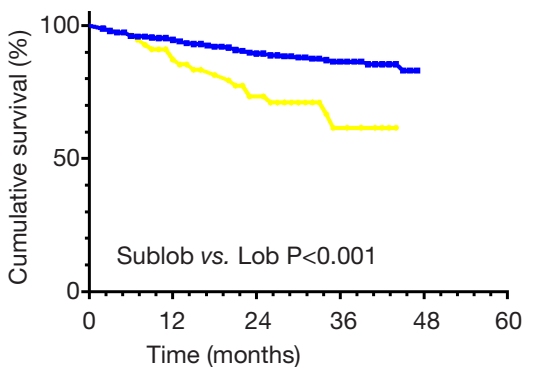

No. at risk

$\begin{array}{lcccccc}\text { Sublob } & 56 & 46 & 36 & 11 & / & \text { / } \\ \text { Lob } & 342 & 304 & 263 & 119 & / & \text { / }\end{array}$

Figure 35 -year overall survival (A,C,E) and lung cancer-specific survival (B,D,F) in patients with stage I squamous cell carcinoma (SCC) $\leq 3$ $\mathrm{cm}$ who underwent lobectomy and sublobectomy in the stratification of tumor size.

on the clinical choices of the surgical approaches among patients with early stage $\mathrm{SCC} \leq 3 \mathrm{~cm}$. Interestingly, the results appeared to demonstrate that a lobectomy had a conspicuous advantage against a sublobectomy only when T1c of SCC occurred, and there was no difference in the survival rate to ever have existed between the two approaches in the T1a and the T1b classification, which was in accordance with our finding above that lobectomy 
Table 3 Cox proportional hazards regressions for patients with squamous cell carcinoma $\leq 3 \mathrm{~cm}$ who underwent sublobectomy or lobectomy

\begin{tabular}{|c|c|c|c|c|c|c|c|c|}
\hline \multirow{3}{*}{ Variable } & \multicolumn{4}{|c|}{ OS } & \multicolumn{4}{|c|}{ LCSS } \\
\hline & \multirow{2}{*}{$\frac{\text { Univariable analysis }}{\mathrm{P}}$} & \multicolumn{3}{|c|}{ Multivariable analysis } & \multirow{2}{*}{$\frac{\text { Univariable analysis }}{\mathrm{P}}$} & \multicolumn{3}{|c|}{ Multivariable analysis } \\
\hline & & $\mathrm{HR}$ & $95 \% \mathrm{Cl}$ & $\mathrm{P}$ & & $\mathrm{HR}$ & $95 \% \mathrm{Cl}$ & $\mathrm{P}$ \\
\hline \multicolumn{9}{|l|}{ Male } \\
\hline \multicolumn{9}{|l|}{ Female } \\
\hline$>60$ & & 1.826 & $1.094-3.048$ & 0.021 & & & & \\
\hline Race & 0.525 & & & & 0.351 & & & \\
\hline \multicolumn{9}{|l|}{ White } \\
\hline \multicolumn{9}{|l|}{ Black } \\
\hline \multicolumn{9}{|l|}{ Yes } \\
\hline Lobe & 0.421 & & & & 0.62 & & & \\
\hline \multicolumn{9}{|l|}{ Upper } \\
\hline \multicolumn{9}{|l|}{ Middle } \\
\hline \multicolumn{9}{|l|}{ Lower } \\
\hline Laterality & 0.385 & & & & 0.706 & & & \\
\hline \multicolumn{9}{|l|}{ Left } \\
\hline \multicolumn{9}{|l|}{ Right } \\
\hline Size $(\mathrm{cm})$ & 0.002 & & & & 0.003 & & & \\
\hline$\leq 1$ & & 1 & (Reference) & & & 1 & (Reference) & \\
\hline \multicolumn{9}{|l|}{ Keratinizing } \\
\hline \multicolumn{9}{|l|}{ Non-keratinizing } \\
\hline \multicolumn{9}{|l|}{ Basaloid } \\
\hline \multicolumn{9}{|l|}{ Clear cell } \\
\hline Unknown & & & & & & & & \\
\hline Differentiation & 0.446 & & & & 0.134 & & & \\
\hline Well & & & & & & & & \\
\hline Moderate & & & & & & & & \\
\hline Poor & & & & & & & & \\
\hline Harvested lymph node & 0.705 & & & & 0.955 & & & \\
\hline$\leq 10$ & & & & & & & & \\
\hline$>10$ & & & & & & & & \\
\hline Pleural invasion & 0.016 & & & & 0.011 & & & \\
\hline No & & 1 & (Reference) & & & 1 & (Reference) & \\
\hline Yes & & 1.378 & $0.983-1.933$ & 0.061 & & 1.581 & $1.002-2.493$ & 0.049 \\
\hline
\end{tabular}


Table 4 Cox proportional hazards regressions for patients with squamous cell carcinoma $\leq 1,>1$ to $\leq 2$ and $>2$ to $\leq 3$ cm in overall survival and lung cancer-specific survival

\begin{tabular}{|c|c|c|c|c|c|c|c|c|c|c|c|c|}
\hline \multirow{3}{*}{ Surgery } & \multicolumn{4}{|c|}{$\mathrm{SCC} \leq 1 \mathrm{~cm}$} & \multicolumn{4}{|c|}{$\mathrm{SCC}>1$ to $\leq 2 \mathrm{~cm}$} & \multicolumn{4}{|c|}{$S C C>2$ to $\leq 3 \mathrm{~cm}$} \\
\hline & \multicolumn{2}{|l|}{ OS } & \multicolumn{2}{|l|}{ LCSS } & \multicolumn{2}{|l|}{ OS } & \multicolumn{2}{|l|}{ LCSS } & \multicolumn{2}{|l|}{ OS } & \multicolumn{2}{|l|}{ LCSS } \\
\hline & $\mathrm{HR}(95 \% \mathrm{Cl})$ & $P$ & $\mathrm{HR}(95 \% \mathrm{Cl})$ & $\mathrm{P}$ & $\mathrm{HR}(95 \% \mathrm{Cl})$ & $P$ & $\mathrm{HR}(95 \% \mathrm{Cl})$ & $\mathrm{P}$ & $\mathrm{HR}(95 \% \mathrm{Cl})$ & $\mathrm{P}$ & $\mathrm{HR}(95 \% \mathrm{Cl})$ & $P$ \\
\hline Sublobectomy & 1 (Reference) & & 1 (Reference) & & 1 (Reference) & & 1 (Reference) & & 1 (Reference) & & 1 (Reference) & \\
\hline Lobectomy & & 0.097 & & 0.788 & & 0.476 & & 0.873 & $0.520(0.322-0.559)$ & 0.008 & $0.413(0.223-0.764)$ & 0.005 \\
\hline
\end{tabular}

SCC, squamous cell carcinoma; OS, overall survival; LCSS, lung cancer-specific survival.

was much more appropriate only under the circumstance of early stage SCC $>2 \mathrm{~cm}$ in size. As for the T2a, parallel survival owing to the invasion of visceral pleura which was inevitably correlated with the high risk of recurrence and death, was exhibited (24-26). In addition, the invasiveness beyond the elastic layer of SCC was much more common than ADC, which also accounted for the less effective treatment option when it was compared with ADC in the early stage patients (27).

To the best of our knowledge, there were also some other prognostic factors in early stage node-negative SCC besides surgical approaches. Previous studies have suggested that gender and age were validated predictors for contributing to the prediction of the personal survival rate (28). In our research, being aged $>60$ was prompted as a risk factor to the overall survival rate, while exerting no statistical influence on cancer-specific survival. Moreover, gender was even shown to have no prognostic effect on the candidates' recurrence and survival rates.

So far, the effective first-line adjuvant chemotherapy for SCC patients was based on platinum (29), while the effectiveness is still uncertain for the patients who had a stage I SCC (30) resection. As for adjuvant radiotherapy, there was no significant distinction in survival rates between the presence and absence of post-radiotherapy in our research. In the stratification analysis, adjuvant radiotherapy demonstrated an even worse clinical outcome in the subgroups of patients with a SCC size of $>1$ to $\leq 2 \mathrm{~cm}$, so the necessity and accuracy of adjuvant radiotherapy for stage I SCC still remains unsettled and needs further investigation.

Lymph node dissection has been discussed extensively, and a significant amount of research has demonstrated the high relevance between a higher harvested lymph node number and the better survival outcome rate among early stage NSCLC patients (31,32). Recently, Liang et al. pointed out the appropriate and recommended number of collected lymph nodes could be 16 for early stage NSCLC patients (33). Meanwhile, in our this research, the count of harvested lymph nodes did not have any statistical effect on the prognosis and survival rate in the early stage SCC patients, likely due to the relatively low prevalence of a metastasis to the reginal and mediastinal lymph nodes, or even in rare cases, the complete lack of metastasis especially in peripheral SCC patients in the early stage $(34,35)$. Therefore, the relationship between early stage SCC and count of harvested lymph nodes should be more deeply explored in feature.

In fact, quite a few of prognostic factors for resection of early stage SCC patients, such as tumor markers $(26,36)$, tumor budding $(18,37)$, and even genetic status $(38,39)$, are emerging. While almost all the predictors above are good for a post-surgical prediction, in this study, our findings were related to the size-specific surgery and associated survival outcome, which could become a model of "presurgical prediction".

There ae several limitations in our research. First of all, it was a retrospective study and the baseline characteristics of the patients and the survival data were all collected from the SEER database and the nature of retrospective and monocentric study could generate inevitable biases and lack representativeness. Second, it is well-known that SCC was classified into central and peripheral subtypes depending on the primary location, and several studies have suggested that the disparities between c-SCC and p-SCC in both the clinicopathological and genetic features, also indicate that those differences do not exist significantly without a lymph node metastasis $(40,41)$. In our study, two subtypes of SCC could not be distinguished due to the limited information of the SEER database which might have resulted in unpredictable deviations even if the distinctions between those two subtypes did not differ statistically. Third, there was a relatively limited sum of patients with inadequate or otherwise potentially confounding parameters such as smoking status, gene mutation and so on, all of which could 
impose limitations on clinical application.

In conclusion, we tried to explore the precise surgical choice of stage I SCC in the SEER database. Lobectomy only demonstrated a better total cancer-specific survival when contrasted with sublobectomy. For stratification analysis, instead of pathological or other characteristics, tumor size could become an excellent indicator for the choice of surgery, which was attested to by the fact that lobectomy was strongly recommended when the size of SCC was $>2$ to $\leq 3 \mathrm{~cm}$, and no statistical difference was present among sizes $\leq 2 \mathrm{~cm}$. PI significantly influenced the clinical outcome of certain surgical procedures among stage I SCC, and lobectomy showed superiority only when the T1c category appeared.

\section{Acknowledgements}

Funding: This work was supported by the National Natural Science Foundation of China (81773007); Shanghai Municipality: Shanghai Rising-Star Program (16QA1403500); Funding for Shanghai Fostering Talents by Shanghai Municipal Human Resources and Social Security Bureau(201706); Outstanding youth program by Shanghai Municipal Commission of Health and Family Planning (2017YQ018).

\section{Footnote}

Conflicts of Interest: The authors have no conflicts of interest to declare.

Ethical Statement: All procedures performed in studies involving human participants were in accordance with the ethical standards of the institutional and/or national research committee and with the 1964 Helsinki declaration and its later amendments or comparable ethical standards. For this type of study formal consent is not required.

\section{References}

1. Siegel R, Naishadham D, Jemal A. Cancer statistics, 2013. CA: Cancer J Clin 2013;63:11-30.

2. Chen $W$, Zheng R, Baade PD, et al. Cancer statistics in China, 2015. CA: Cancer J Clin 2016;66:115-32.

3. Poleri C, Morero JL, Nieva B, et al. Risk of recurrence in patients with surgically resected stage I non-small cell lung carcinoma: Histopathologic and immunohistochemical analysis. Chest 2003;123:1858-67.
4. Travis WD. Pathology of lung cancer. Clin Chest Med 2011;32:669-92.

5. Christensen JD, Chiles C. Low-Dose Computed Tomographic Screening for Lung Cancer. Clin Chest Med 2015;36:147-60.

6. Kinoshita T, Ohtsuka T, Yotsukura M, et al. Prognostic impact of preoperative tumor marker levels and lymphovascular invasion in pathological stage I adenocarcinoma and squamous cell carcinoma of the lung. J Thorac Oncol 2015;10:619-28.

7. Ginsberg RJ, Rubinstein LV. Randomized trial of lobectomy versus limited resection for T1 N0 non-small cell lung cancer. Lung Cancer Study Group. Ann Thorac Surg 1995;60:615-22, discussion 622-3.

8. Thomas P, Rubinstein L. Cancer recurrence after resection: T1 N0 non-small-cell lung cancer-Lung Cancer Study Group. Ann Thorac Surg 1990;49:242-6; discussion 246-7.

9. McKenna RJ Jr. Surgical management of primary lung cancer. Semin Oncol 2007;34:250-5.

10. Veluswamy RR, Ezer N, Mhango G, et al. Limited Resection Versus Lobectomy for Older Patients With Early-Stage Lung Cancer: Impact of Histology. J Clin Oncol 2015;33:3447-53.

11. Landreneau RJ, Normolle DP, Christie NA, et al. Recurrence and Survival Outcomes After Anatomic Segmentectomy Versus Lobectomy for Clinical Stage I Non-Small-Cell Lung Cancer: A Propensity-Matched Analysis. J Clin Oncol 2014;32:2449-55.

12. Dai C, Shen J, Ren Y, et al. Choice of Surgical Procedure for Patients With NSCLC 5BAuthor\%5D\&cauthor=true \&cauthor_uid=27382092" .+Christie.+Recurrence+and+S uulation-Based Study. J Clin Oncol 2016;34:3175-82.

13. Reveliotis K, Kalavrouziotis G, Skevis K, et al. Wedge resection and segmentectomy in patients with stage I nonsmall cell lung carcinoma. Oncol Rev 2014;8:234.

14. National Cancer Institute: Surveillance, Epidemiology, and End Results. Available online: http://www.seer. cancer.gov

15. Chansky K, Sculier JP, Crowley JJ, et al. The International Association for the Study of Lung Cancer Staging Project: prognostic factors and pathologic TNM stage in surgically managed non-small cell lung cancer. J Thorac Oncol 2009;4:792-801.

16. Fukui T, Taniguchi T, Kawaguchi K, et al. Comparisons of the clinicopathological features and survival outcomes between lung cancer patients with adenocarcinoma and squamous cell carcinoma. Gen Thorac Cardiovasc Surg 
2015;63:507-13.

17. Liu S, Wang R, Zhang Y, et al. Precise Diagnosis of Intraoperative Frozen Section Is an Effective Method to Guide Resection Strategy for Peripheral Small-Sized Lung Adenocarcinoma. J Clin Oncol 2016;34:307-13.

18. Kadota K, Nitadori J, Woo KM, et al. Comprehensive pathological analyses in lung squamous cell carcinoma: single cell invasion, nuclear diameter, and tumor budding are independent prognostic factors for worse outcomes. J Thorac Oncol 2014;9:1126-39.

19. Pilotto S, Sperduti I, Novello S, et al. Risk Stratification Model for Resected Squamous-Cell Lung Cancer Patients According to Clinical and Pathological Factors. J Thorac Oncol 2015;10:1341-8.

20. Travis W, Brambilla E, Muller-Hermelink H, et al. World Health Organization Classification of Tumours. Pathology and Genetics. Tumours of the Lung, Pleura, Thymus, and Heart. Lyon, France: IARC Press; 2004.

21. Reveliotis K, Kalavrouziotis G, Skevis K, et al. Wedge resection and segmentectomy in patients with stage I nonsmall cell lung carcinoma. Oncol Rev 2014;8:234.

22. Detterbeck FC, Boffa DJ, Kim AW, et al. The Eighth Edition Lung Cancer Stage Classification. Chest 2017;151:193-203.

23. Travis WD, Brambilla E, Nicholson AG, et al. The 2015 World Health Organization Classification of Lung Tumors Impact of Genetic, Clinical and Radiologic Advances Since the 2004 Classification. J Thorac Oncol 2015;10:1243-60.

24. Shimada Y, Saji H, Yoshida K, et al. Pathological vascular invasion and tumor differentiation predict cancer recurrence in stage IA non-small-cell lung cancer after complete surgical resection. J Thorac Oncol 2012;7:1263-70.

25. Yilmaz A, Duyar SS, Cakir E, et al. Clinical impact of visceral pleural, lymphovascular and perineural invasion in completely resected non-small cell lung cancer. Eur J Cardiothorac Surg 2011;40:664-70.

26. Kinoshita T, Ohtsuka T, Hato T, et al. Prognostic factors based on clinicopathological data among the patients with resected peripheral squamous cell carcinomas of the lung. J Thorac Oncol 2014;9:1779-87.

27. Kawase A, Yoshida J, Miyaoka E, et al.; Japanese Joint Committee of Lung Cancer Registry. Visceral pleural invasion classification in non-small-cell lung cancer in the 7 th edition of the tumor, node, metastasis classification for lung cancer: validation analysis based on a large-scale nationwide database. J Thorac Oncol 2013;8:606-11.

28. Agarwal M, Brahmanday G, Chmielewski GW, et al. Age, tumor size, type of surgery, and gender predict survival in early stage (stage I and II) non-small cell lung cancer after surgical resection. Lung Cancer 2010;68:398-402.

29. Thatcher N, Hirsch FR, Luft AV, et al, for the SQUIRE Investigators. Necitumumab plus gemcitabine and cisplatin versus gemcitabine and cisplatin alone as fi rst-line therapy in patients with stage IV squamous non-small-cell lung cancer (SQUIRE): an open-label, randomised, controlled phase 3 trial. Lancet Oncol 2015;16:763-74.

30. Pignon JP, Tribodet H, Scagliotti GV, et al. Lung adjuvant cisplatin evaluation: a pooled analysis by the LACE Collaborative Group. J Clin Oncol 2008;26:3552-9.

31. Gajra A, Newman N, Gamble GP, et al. Effect of number of lymph nodes sampled on outcome in patients with stage I nonsmall-cell lung cancer. J Clin Oncol 2003;21:1029-34.

32. Osarogiagbon RU, Ogbata O, Yu X. Number of lymph nodes associated with maximal reduction of long-term mortality risk in pathologic node-negative non-small cell lung cancer. Ann Thorac Surg 2014;97:385-93.

33. Liang W, He J, Shen $Y$, et al. Impact of examined lymph node count on precise staging and long-term survival of resected non-small-cell lung cancer: A population study of the US SEER database and a Chinese multi-institutional registry. J Clin Oncol 2017;35:1162-70.

34. Ohta Y, Oda M, Wu J, et al. Can tumor size be a guide for limited surgical intervention in patients with peripheral non-small cell lung cancer? Assessment from the point of view of nodal micrometastasis. J Thorac Cardiovasc Surg 2001;122:900-6.

35. Sakurai H, Asamura H, Watanabe S, et al. Clinicopathologic features of peripheral squamous cell carcinoma of the lung. Ann Thorac Surg 2004;78:222-7.

36. Tas F, Aydiner A, Topuz E, et al. Utility of the serum tumor markers: CYFRA 21.1, carcinoembryonic antigen (CEA), and squamous cell carcinoma antigen (SCC) in squamous cell lung cancer. J Exp Clin Cancer Res 2000;19:477-81.

37. Masuda R, Kijima H, Imamura N, et al. Tumor budding is a significant indicator of a poor prognosis in lung squamous cell carcinoma patients. Mol Med Rep 2012;6:937-43.

38. Noro R, Ishigame T, Walsh N, et al. A two-gene prognostic classifier for early-stage lung squamous cell carcinoma in multiple large-scale and geographically diverse cohorts. J Thorac Oncol 2017;12:65-76.

39. Pan Y, Wang R, Ye T, et al. Comprehensive Analysis of Oncogenic Mutations in Lung Squamous Cell 
Carcinoma With Minor Glandular Component. Chest 2014;145:473-9.

40. Saijo T, Ishii G, Nagai K, et al. Differences in clinicopathological and biological features between central-type and peripheral-type squamous cell carcinoma of the lung. Lung Cancer 2006;52:37-45.

41. Funai K, Yokose T, Ishii G, et al. Clinicopathologic characteristics of peripheral squamous cell carcinoma of the lung. Am J Surg Pathol 2003;27:978-84.

Cite this article as: Chen C, Wang Y, Pan X, Fu S, Shi Y, Yang J, Wang R. Choice of the surgical approach for patients with stage I lung squamous cell carcinoma $\leq 3 \mathrm{~cm}$. J Thorac Dis 2018;10(12):6771-6782. doi: 10.21037/jtd.2018.11.51 
A

Overall survival squamous carcinoma in T1

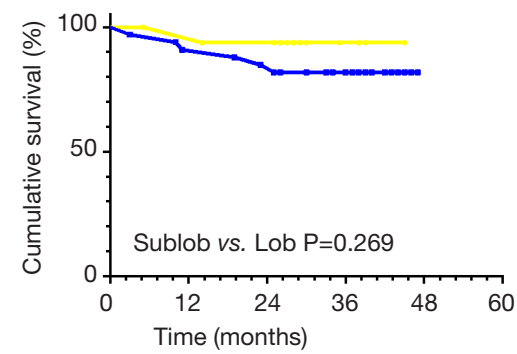

No. at risk

Sublob

Lob

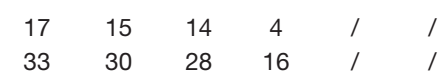

C

Overall survival

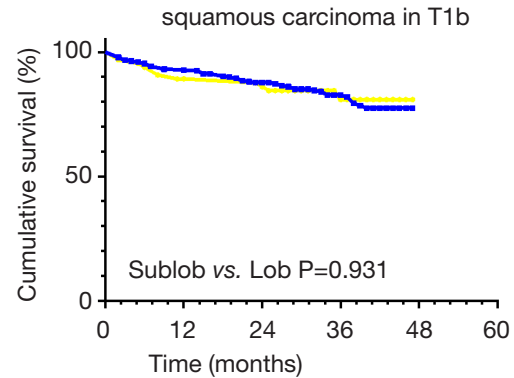

No. at risk

$\begin{array}{lllllll}\text { Sublob } & 65 & 57 & 52 & 22 & /\end{array}$

Lob

E

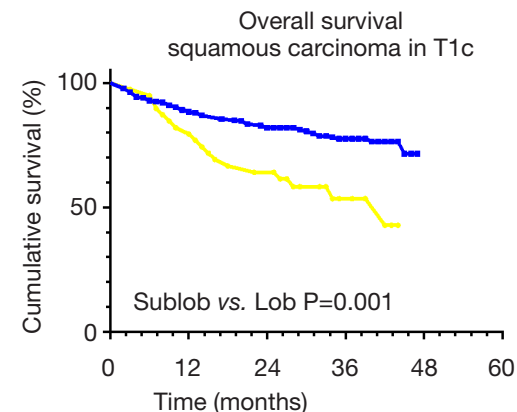

No. at risk

$\begin{array}{lllllll}\text { Sublob } & 39 & 31 & 25 & 9 & /\end{array}$

Lob

$\begin{array}{llll}268 & 236 & 219 & 103\end{array}$

G

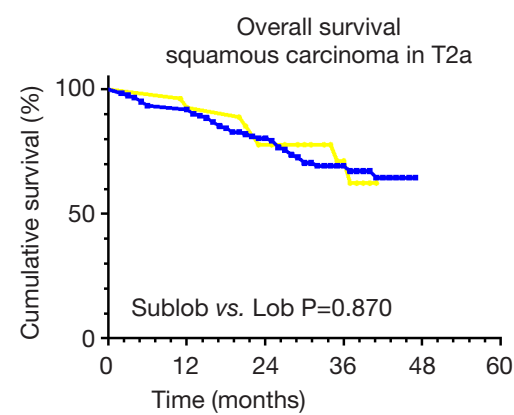

No. at risk

Sublob

Lob
B

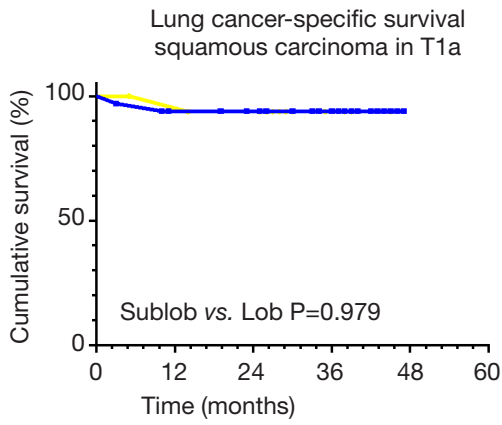

No. at risk

$\begin{array}{llllcll}\text { Sublob } & 17 & 15 & 14 & 4 & / & \text { / }\end{array}$

$\mathrm{D}$ Lung cancer-specific survival squamous carcinoma in $\mathrm{T} 1 \mathrm{~b}$

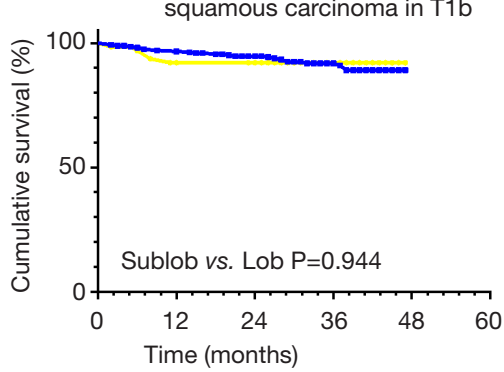

No. at risk

$\begin{array}{lcccccc}\text { Sublob } & 65 & 57 & 52 & 22 & / & /\end{array}$

$\mathrm{F}$

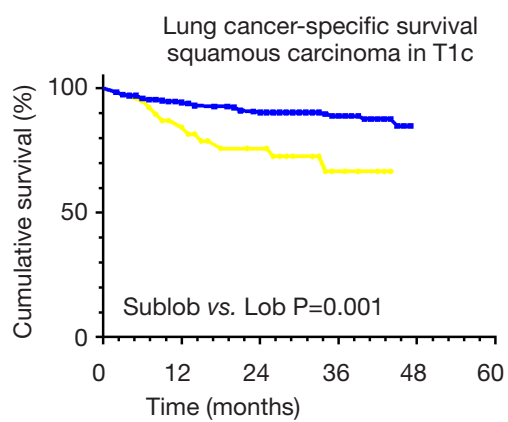

No. at risk

$\begin{array}{llllcll}\text { Sublob } & 39 & 31 & 25 & 9 & / & /\end{array}$

$\mathrm{H}$

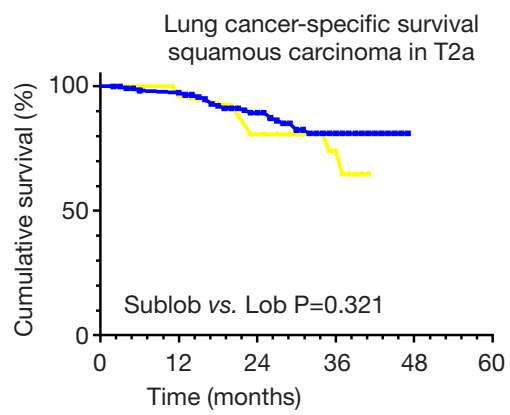

No. at risk

$\begin{array}{lcccccc}\text { Sublob } & 27 & 25 & 21 & 8 & / & \text { / } \\ \text { Lob } & 122 & 112 & 93 & 33 & / & \text { / }\end{array}$

Figure S1 5 -year overall survival (A,C,E) and lung cancer-specific survival (B,D,F) in patients with stage I SCC $\leq 3 \mathrm{~cm}$ who underwent lobectomy and sublobectomy in the stratification of $\mathrm{T}$ category. 
Table S1 Clinicopathological characteristics of patients with pT1-2aN0M0 squamous cell carcinoma $\leq 3 \mathrm{~cm}$

\begin{tabular}{|c|c|c|c|c|c|c|c|c|c|c|c|c|}
\hline \multirow[b]{2}{*}{ Characteristics } & \multicolumn{3}{|c|}{ T1a } & \multicolumn{3}{|c|}{$\mathrm{T} 1 \mathrm{~b}$} & \multicolumn{3}{|c|}{$\mathrm{T} 1 \mathrm{c}$} & \multicolumn{3}{|c|}{$\mathrm{T} 2 \mathrm{a}$} \\
\hline & $\begin{array}{l}\text { Sublobectomy } \\
\qquad(\mathrm{N}=17)\end{array}$ & $\begin{array}{l}\text { Lobectomy } \\
\qquad(\mathrm{N}=33)\end{array}$ & $\mathrm{P}$ & $\begin{array}{l}\text { Sublobectomy } \\
\qquad(\mathrm{N}=65)\end{array}$ & $\begin{array}{l}\text { Lobectomy } \\
\qquad(\mathrm{N}=278)\end{array}$ & $P$ & $\begin{array}{l}\text { Sublobectomy } \\
\qquad(\mathrm{N}=39)\end{array}$ & $\begin{array}{l}\text { Lobectomy } \\
\qquad(\mathrm{N}=268)\end{array}$ & $\mathrm{P}$ & $\begin{array}{l}\text { Sublobectomy } \\
\qquad(\mathrm{N}=27)\end{array}$ & $\begin{array}{l}\text { Lobectomy } \\
\qquad(\mathrm{N}=122)\end{array}$ & $\mathrm{P}$ \\
\hline Sex & & & 0.012 & & & 0.799 & & & 0.446 & & & 0.523 \\
\hline Male & 3 & 18 & & 33 & 146 & & 19 & 148 & & 13 & 67 & \\
\hline Female & 14 & 15 & & 32 & 132 & & 20 & 120 & & 14 & 55 & \\
\hline Age (years) & & & 0.692 & & & 0.663 & & & 0.016 & & & 0.064 \\
\hline$\leq 60$ & 1 & 3 & & 8 & 40 & & 1 & 47 & & 0 & 14 & \\
\hline$>60$ & 16 & 30 & & 57 & 238 & & 38 & 221 & & 27 & 108 & \\
\hline Race & & & 0.581 & & & 0.632 & & & 0.564 & & & 0.377 \\
\hline White & 15 & 27 & & 56 & 248 & & 33 & 234 & & 24 & 108 & \\
\hline Black & 2 & 4 & & 5 & 20 & & 5 & 22 & & 3 & 8 & \\
\hline Others & 0 & 2 & & 4 & 10 & & 1 & 12 & & 0 & 6 & \\
\hline Post-radiotherapy & & & NA & & & 0.756 & & & & & & 0.196 \\
\hline No & 17 & 33 & & 64 & 275 & & 38 & 264 & 0.621 & 25 & 119 & \\
\hline Yes & 0 & 0 & & 1 & 3 & & 1 & 4 & & 2 & 3 & \\
\hline Lobe & & & 0.920 & & & 0.150 & & & 0.436 & & & 0.702 \\
\hline Upper & 13 & 24 & & 41 & 174 & & 24 & 167 & & 19 & 77 & \\
\hline Middle & 1 & 3 & & 1 & 22 & & 0 & 10 & & 2 & 8 & \\
\hline Lower & 3 & 6 & & 23 & 82 & & 15 & 91 & & 6 & 37 & \\
\hline Laterality & & & 0.903 & & & 0.173 & & & 0.558 & & & 0.986 \\
\hline Left & 7 & 13 & & 31 & 107 & & 20 & 124 & & 12 & 54 & \\
\hline Right & 10 & 20 & & 34 & 171 & & 19 & 144 & & 15 & 68 & \\
\hline Pathology & & & 0.690 & & & 0.740 & & & 0.740 & & & 0.956 \\
\hline Keratinizing & 1 & 1 & & 5 & 13 & & 4 & 13 & & 1 & 7 & \\
\hline Non-keratinizing & 0 & 1 & & 1 & 8 & & 1 & 13 & & 1 & 5 & \\
\hline Basaloid & 0 & 0 & & 0 & 2 & & 0 & 3 & & 0 & 1 & \\
\hline Clear cell & 0 & 0 & & 0 & 1 & & 0 & 1 & & 0 & 1 & \\
\hline Unknown & 16 & 31 & & 59 & 254 & & 34 & 238 & & 25 & 108 & \\
\hline Differentiation & & & 0.945 & & & 0.821 & & & 0.604 & & & 0.652 \\
\hline Well & 2 & 4 & & 5 & 16 & & 1 & 6 & & 0 & 3 & \\
\hline Moderate & 8 & 17 & & 36 & 153 & & 16 & 133 & & 14 & 67 & \\
\hline Poor & 7 & 12 & & 24 & 109 & & 22 & 129 & & 13 & 52 & \\
\hline $\begin{array}{l}\text { Harvested lymph } \\
\text { node }\end{array}$ & & & 0.010 & & & $<0.001$ & & & 0.039 & & & 0.067 \\
\hline$\leq 10$ & 15 & 17 & & 57 & 180 & & 30 & 160 & & 22 & 77 & \\
\hline$>10$ & 2 & 16 & & 8 & 98 & & 9 & 108 & & 5 & 45 & \\
\hline
\end{tabular}


Table S2 Cox proportional hazards regressions for patients with pT1-2aN0M0 squamous cell carcinoma $\leq 3 \mathrm{~cm}$ in overall survival and lung cancer-specific survival

\begin{tabular}{|c|c|c|c|c|c|c|c|c|c|c|c|c|c|c|c|c|}
\hline \multirow{3}{*}{ Characteristics } & \multicolumn{4}{|c|}{ T1a } & \multicolumn{4}{|c|}{$\mathrm{T} 1 \mathrm{~b}$} & \multicolumn{4}{|c|}{ T1c } & \multicolumn{4}{|c|}{ T2a } \\
\hline & \multicolumn{2}{|l|}{ os } & \multicolumn{2}{|l|}{ LCSS } & \multicolumn{2}{|l|}{ os } & \multicolumn{2}{|l|}{ LCSS } & \multicolumn{2}{|l|}{ os } & \multicolumn{2}{|l|}{ LCSS } & \multicolumn{2}{|l|}{ os } & \multicolumn{2}{|c|}{ LCSS } \\
\hline & $\mathrm{HR}(95 \% \mathrm{Cl})$ & $P$ & $\mathrm{HR}(95 \% \mathrm{Cl})$ & $P$ & $\mathrm{HR}(95 \% \mathrm{Cl})$ & $P$ & HR (95\%Cl) & $P$ & HR $(95 \% \mathrm{Cl})$ & $P$ & HR $(95 \% \mathrm{Cl})$ & $P$ & $\mathrm{HR}(95 \% \mathrm{Cl})$ & $P$ & $\mathrm{HR}(95 \% \mathrm{Cl})$ & $P$ \\
\hline \multicolumn{17}{|l|}{ Sex } \\
\hline Male & 1 (Ref) & & 1 (Ref) & & 1 (Ref) & & 1 (Ref) & & 1 (Ref) & & 1 (Ref) & & 1 (Ref) & & 1 (Ref) & \\
\hline Female & & 1.000 & & 1.000 & & 0.414 & & 0.118 & & 0.058 & & 0.412 & & 0.844 & & 0.473 \\
\hline \multicolumn{17}{|l|}{ Age (years) } \\
\hline$\leq 60$ & 1 (Ref) & & 1 (Ref) & & 1 (Ref) & & 1 (Ref) & & 1 (Ref) & & 1 (Ref) & & 1 (Ref) & & 1 (Ref) & \\
\hline$>60$ & & 1.000 & & 1.000 & & 0.398 & & 0.396 & & 0.357 & & 0.346 & & 0.126 & & 0.440 \\
\hline \multicolumn{17}{|l|}{ Race } \\
\hline White & 1 (Ref) & & 1 (Ref) & & 1 (Ref) & & 1 (Ref) & & 1 (Ref) & & 1 (Ref) & & 1 (Ref) & & 1 (Ref) & \\
\hline Black & & 1.000 & & 1.000 & & 0.926 & & 0.508 & & 0.639 & & 0.581 & & 0.166 & & 0.191 \\
\hline Others & & 1.000 & & 1.000 & & 0.738 & & 0.978 & & 0.798 & & 0.714 & & 0.399 & & 0.919 \\
\hline \multicolumn{17}{|l|}{ Post-radiotherapy } \\
\hline No & & NA & & NA & 1 (Ref) & & 1 (Ref) & & 1 (Ref) & & 1 (Ref) & & 1 (Ref) & & 1 (Ref) & \\
\hline Yes & & & & & & 0.088 & $\begin{array}{c}8.046 \\
(1.476-44.05)\end{array}$ & 0.016 & & 0.326 & & 0.507 & & 0.783 & & 0.790 \\
\hline \multicolumn{17}{|l|}{ Lobe } \\
\hline Upper & 1 (Ref) & & 1 (Ref) & & 1 (Ref) & & 1 (Ref) & & 1 (Ref) & & 1 (Ref) & & 1 (Ref) & & 1 (Ref) & \\
\hline Middle & & 1.000 & & 1.000 & & 0.584 & & 0.635 & & 0.793 & & 0.770 & & 0.548 & & 0.709 \\
\hline Lower & & 1.000 & & 1.000 & & 0.369 & & 0.519 & & 0.670 & & 0.504 & & 0.466 & & 0.729 \\
\hline \multicolumn{17}{|l|}{ Laterality } \\
\hline Left & 1 (Ref) & & 1 (Ref) & & 1 (Ref) & & 1 (Ref) & & 1 (Ref) & & 1 (Ref) & & 1 (Ref) & & 1 (Ref) & \\
\hline Right & & 1.000 & & 1.000 & & 0.056 & & 0.109 & & 0.799 & & 0.829 & & 0.140 & $\begin{array}{c}2.615 \\
(1.042-6.560)\end{array}$ & 0.041 \\
\hline \multicolumn{17}{|l|}{ Surgery } \\
\hline Sublobectomy & 1 (Ref) & & 1 (Ref) & & 1 (Ref) & & 1 (Ref) & & 1 (Ref) & & 1 (Ref) & & 1 (Ref) & & 1 (Ref) & \\
\hline Lobectomy & & 1.000 & & 1.000 & & 0.739 & & 0.873 & $\begin{array}{c}0.385 \\
(0.220-0.673)\end{array}$ & 0.001 & $\begin{array}{c}0.309 \\
(0.146-0.653)\end{array}$ & 0.002 & & 0.554 & & 0.541 \\
\hline \multicolumn{17}{|l|}{ Pathology } \\
\hline Keratinizing & 1 (Ref) & & 1 (Ref) & & 1 (Ref) & & 1 (Ref) & & 1 (Ref) & & 1 (Ref) & & 1 (Ref) & & 1 (Ref) & \\
\hline Non-keratinizing & & 1.000 & & 1.000 & & 0.970 & & 0.949 & & 0.367 & & 0.257 & & 0.882 & & 0.911 \\
\hline Basaloid & & NA & & NA & & 0.987 & & 0.979 & & 0.384 & & 0.190 & & 0.962 & & 0.971 \\
\hline Clear cell & & NA & & NA & & 0.991 & & 0.984 & & 0.972 & & 0.982 & & 0.957 & & 0.970 \\
\hline Unknown & & 1.000 & & 1.000 & & 0.318 & & 0.816 & & 0.452 & & 0.597 & & 0.962 & & 0.918 \\
\hline Differentiation & & & & & & & & & & & & & & & & \\
\hline Well & 1 (Ref) & & 1 (Ref) & & 1 (Ref) & & 1 (Ref) & & 1 (Ref) & & 1 (Ref) & & 1 (Ref) & & 1 (Ref) & \\
\hline Moderate & & 1.000 & & 1.000 & & 0.350 & & 0.927 & & 0.735 & & 0.913 & & 0.918 & & 0.943 \\
\hline Poor & & 1.000 & & 1.000 & & 0.454 & & 0.927 & & 0.596 & & 0.698 & & 0.914 & & 0.938 \\
\hline $\begin{array}{l}\text { Harvested lymph } \\
\text { node }\end{array}$ & & & & & & & & & & & & & & & & \\
\hline$\leq 10$ & 1 (Ref) & & 1 (Ref) & & 1 (Ref) & & 1 (Ref) & & 1 (Ref) & & 1 (Ref) & & 1 (Ref) & & 1 (Ref) & \\
\hline$>10$ & & 1.000 & & 1.000 & & 0.581 & & 0.433 & & 0.951 & & 0.597 & & 0.867 & & 0.631 \\
\hline
\end{tabular}

